\title{
Política, sociedad y religión en Arequipa: una mirada desde el laicado católico militante (1885- 1919)*
}

Politics, Society and Religion in Arequipa: an approach from the militant Catholic laity (1885-1919)

ROLANDO IBERICO RUIZ

https://orcid.org/0000-0003-2967-4036

Pontificia Universidad Católica del Perú

ribericor@pucp.pe

\section{RESUMEN}

El articulo analiza la relación entre la religión, la sociedad y la política a partir de la militancia laical en Arequipa. Durante el periodo de estudio, se identifican dos paradigmas influenciados por la comprensión episcopal del contexto sociopolítico. El primer paradigma estuvo caracterizado por el afán de "cristianizar» las instituciones sociales y politicas del país, es decir, de monopolizar las instituciones del estado. En un segundo momento, las sociedades católicas buscaron mantener la presencia del catolicismo en la sociedad y la política mediante la intervención en ella. A través de sus acciones públicas, los católicos laicos daban cuenta de un reconocimiento tácito de la realidad de emergente pluralidad de opciones sociales y politicas en Arequipa.

Palabras clave: laicado militante, Arequipa, catolicismo social, sociedades católicas, Partido Católico del Perú

* Este estudio es resultado del proyecto DGI 2016-1-0037/00356, «Una ciudad de Dios en el Perú: la formación de la Arequipa católica, 1856-1925», financiado por la Dirección de Gestión de la Investigación de la Pontificia Universidad Católica del Perú.

HISTORICn XLV.1 (2021): 111-151 / e-ISSN 2223-375X

https://doi.org/10.18800/historica.202101.004 


\section{ABSTRACT}

The article analyzes the relationship between religion, society and politics from the perspective of militant Catholic laity in Arequipa. The study identifies two paradigms to understand this relationship influenced by the episcopal understanding of the socio-political context. The first paradigm was characterized by the desire to "Christianize» the country's social and political institutions, that is, to monopolize the state institutions. The second paradigm, the Catholic societies sought to maintain the presence of Catholicism in society and politics by intervening in them. Through the public actions, the Catholic laity gave an implicit recognition of the emerging plurality of social and political options in Arequipa. Keywords: militant laity, Arequipa, Social Catholicism, Catholic societies, Catholic Party of Peru

1 destacado historiador de la Iglesia Hubert Jedin afirmó que «la
historia de la vida de la Iglesia católica desde mediados del siglo XIX es en buena parte la historia de las asociaciones católicas». ${ }^{1}$ Arequipa no fue la excepción a esta tendencia del catolicismo decimonónico. Desde la segunda mitad del siglo XIX, los laicos arequipeños asumieron como los marcos de referencia para la intervención de la Iglesia en la vida del país, la esfera pública y los valores republicanos. De esta manera, a pesar de la intención apologética y monopolizadora, la participación del laicado en el espacio público significó implícitamente el reconocimiento de la pluralidad política e ideológica en Arequipa. Ello no significó necesariamente la aceptación ni el reconocimiento de la validez de dicha pluralidad. Como se analiza en este estudio, la militancia católica movió el catolicismo hacia la necesidad de fundamentar su presencia en un mundo en el cual no todos eran creyentes y donde existían ideologías cuestionadoras del orden católico. ${ }^{2}$

${ }^{1}$ Jedin 1978, VIII: 314.

2 Como afirma Charles Taylor, el proceso secularizador implicó el abandono del «trasfondo ingenuo» al "trasfondo reflexivo», es decir de una concepción del mundo en el 
Los estudios historiográficos sobre el catolicismo han puesto de manifiesto dos procesos centrales que permiten entender la historia política, ideológica y religiosa en Europa y América Latina. En primer lugar, la consolidación institucional y doctrinal de la Iglesia católica abanderada por el ultramontanismo y, en segundo lugar, el proceso de resurgimiento de la vida intelectual, doctrinal y litúrgica del catolicismo desde la segunda mitad del siglo XIX. ${ }^{3}$ La vida institucional del catolicismo se consolidó como consecuencia del proceso político abierto por las revoluciones atlánticas, que introdujeron nuevos valores políticos como la libertad, el individualismo, la tolerancia de cultos y la autonomía de lo temporal. El papado y los episcopados perdieron de forma progresiva el poder político, social y cultural como consecuencia de la nueva legitimidad secular surgida de la Francia revolucionaria y trasmitida hacia el resto de occidente. ${ }^{4}$ En este escenario, la Iglesia atravesó un reacomodamiento político marcado por un proceso de institucionalización, romanización y resurgimiento en la esfera pública. Como consecuencia, desde mediados del siglo XIX, los laicos y laicas emergieron como actores de la nueva reconfiguración eclesial.

En el Perú, la historiografía reconoce la identidad católica de la ciudad de Arequipa. Esta vinculación con el catolicismo se consolidó desde mediados del siglo XIX y se extendió hasta las primeras décadas del siglo XX. Arequipa se convirtió en un espacio donde la identidad religiosa sirvió como plataforma para reivindicaciones regionales y permitió articular la identidad local en oposición al creciente centralismo y liberalismo de Lima. ${ }^{5}$ Con el soporte institucional e ideológico de sus obispos, el catolicismo laical arequipeño articuló una cultura política católica a partir del lenguaje pontificio antiliberal y las reivindicaciones políticas locales. Por ello, el estudio del catolicismo arequipeño permite comprender la complejidad del proceso de recepción y adaptación del

cual todos eran creyentes a un reconocimiento de la pluralidad de creencias y opciones de vida (Taylor 2014: 37-39).

3 Ivereigh 2000; Clark y Kaiser 2003 y Burleigh 2005.

${ }^{4}$ Uertz 2011: 56.

5 Klaiber 1988; García Jordán 1991; Armas Asín 1998 y Martin 2012. 
lenguaje teológico-político del pontificado y el proceso del resurgimiento católico. Este proceso se dio en el marco de la modernización política, económica y cultural de la ciudad que permitió articular una cultura política católica en Arequipa, vivida desde la identidad local y religiosa. Como muestra este estudio, la militancia laical jugó un papel crucial como promotora de la identidad religiosa de la ciudad tanto a nivel apologético como social, y fue una de las plataformas de la identidad católica de la ciudad.

De estos procesos globales del catolicismo occidental y latinoamericano, surge el laicado militante como un actor clave de estos cambios. La militancia católica se define como «el seglar que ha asumido una responsabilidad apostólica» con la finalidad de sostener públicamente el trabajo de la Iglesia. ${ }^{6}$ En los estudios del catolicismo, se considera que la consciencia militante despierta entre los laicos cuando se inicia la Acción Católica, sus grupos especializados, y se asocia a la actitud cerrada e intransigente de la jerarquía en relación a la sociedad y el estado. ${ }^{7}$ Sin embargo, la militancia católica nace de la mano con el afianzamiento del ultramontanismo y la progresiva consolidación de la esfera pública desde mediados del siglo XIX.

La militancia laical surgió con dos finalidades: (1) defender los derechos de la Iglesia ante el estado, y (2) abordar la «cuestión social». Con ello, la militancia católica se involucró en la discusión sobre la forma de la república y la sociedad. Es decir, por un lado, si la república debía constituirse sobre bases jurídicas y morales católicas y cómo debía ubicarse en este entramado la misma Iglesia. Por otro lado, ante el fracaso de consolidar un estado católico, la "cuestión social» permitió abrir nuevos escenarios para pensar la presencia de los católicos en la esfera pública

6 Vaca 2005: 74.

7 Para el Perú, Klaiber ubica el inicio del laicado militante en la década de 1930 cuando surge la Acción Católica Peruana (Klaiber 1988: 41-43, 281-332). Sin embargo, la militancia laical se constituye desde la segunda mitad de 1860 con la Sociedad PeruanoCatólica. Otros estudios contextualizan el surgimiento de la militancia católica en el siglo XX. Véanse Blasco 2005; Vaca 2005; y López 2017. Sobre la aparición de la noción de «acción católica» en el Perú, consultar Ara Goñi 2019. 
y en la construcción de la sociedad. La problemática social permitió articular modelos sociales regidos por valores cristianos en los cuales la Iglesia se sentía como una suerte de guía moral. Por ello, el catolicismo social dio paso a organizaciones políticas católicas que permitiesen que la militancia católica tuviera un rol en la construcción de narrativas políticas y sociales sobre el país. Ese fue el caso del Partido Católico.

Por lo tanto, el presente artículo estudia la historia del catolicismo arequipeño desde la perspectiva de la militancia laical y su involucramiento en temas sociales y políticos de la ciudad, realizada siempre en colaboración con los obispos de Arequipa. El artículo inicia con una contextualización del catolicismo en Arequipa para luego analizar los dos paradigmas de la militancia católica. El primer paradigma se caracterizó por la dimensión apologético-política como «cristianización» del estado y la sociedad que fue influenciado por los episcopados de José Ambrosio Huerta y Manuel Segundo Ballón (1898-1905). Mientras que el segundo, promovido por el obispo Mariano Holguín (1906-1945), estuvo marcado por el giro progresivo hacia la intervención social y política para influenciar en la construcción de una "sociedad católica» en Arequipa. La conclusión cierra dando cuenta de la progresiva aparición de una consciencia de pertenencia eclesial en el contexto de cambios de Arequipa y de reacomodo eclesial.

«LA ROMA DEL PERÚ»: CATOLICISMO GLOBAL Y REPUBLICANO EN AREQUIPA Los pontificados de Gregorio XVI (1831-1846) y Pio IX (1846-1878) fueron centrales para la consolidación de la postura antimoderna del discurso político católico. Ambos pontífices sentaron las bases para la formación de una nueva sensibilidad católica opuesta a los valores modernos con un registro lingüístico antimoderno y con propuestas teológico-políticas de carácter transnacional. La política pontificia contra los valores de la modernidad y la centralización del poder eclesial en Roma se apoyó en el ultramontanismo. Los ultramontanos constituían un movimiento surgido como reacción a algunos grupos católicos favorables a la intervención del estado en la vida de las iglesias locales. Para ellos, la Iglesia constituía una «sociedad perfecta», es decir, una sociedad 
autónoma y superior moral, espiritual y sobrenaturalmente respecto a la sociedad humana y al Estado. En el plano religioso, defendieron la infalibilidad pontificia, promovían las devociones, reforzaron las prácticas católicas como la misa y los sacramentos, se preocuparon por la educación de los niños y jóvenes y realzaron el papel de las mujeres como agentes centrales de la familia y la caridad. ${ }^{8}$ El concilio Vaticano I (18691870), convocado por Pio IX, promulgó el dogma de la infalibilidad papal, aseguró la organización jerárquica y centralizada de la Iglesia y dio muestra de la unidad doctrinal católica. Era la victoria doctrinal y teológica del ultramontanismo.

En el Perú, la Iglesia logró conservar su legitimidad social, cultural y política luego de la independencia. Desde la segunda mitad del siglo XIX, se abrió un proceso intenso de reformas liberales que buscaron consolidar política y económicamente al Estado y que afectaron los intereses eclesiales. ${ }^{9}$ El conflicto con los liberales permitió paradójicamente fortalecer internamente a la Iglesia católica, pues se afianzaron aquellos defensores de la autoridad pontificia, del reconocimiento del patronato como concesión pontificia y de la autonomía eclesial en asuntos internos. Este proceso se sustentó en la teología ultramontana que legitimaba los cambios institucionales del catolicismo y deslegitimaba a los católicos liberales y regalistas. El lenguaje ultramontano peruano bebía de las fuentes romanas y su actitud de rechazo frente al liberalismo y las prerrogativas estatales respecto de la Iglesia. ${ }^{10}$

En el Perú, el catolicismo ultramontano se consolidó con el surgimiento de sociedades laicales que forjaron una militancia católica, liderada por clérigos ultramontanos. En un primer momento, predominaron la romanización y la progresiva expansión teológico-eclesial del ultramontanismo en los ambientes clericales (1830-1850). Este proceso consolidó progresivamente el catolicismo peruano en términos doctrinales e institucionales. La segunda etapa se abre hacia fines de la década de 1850, cuando los laicos peruanos se involucran activamente en la defensa del

\footnotetext{
8 Anderson 2000: 33; Iberico Ruiz 2016: 31-32.

9 Pike 1967; Sobrevilla 2002 y 2004.

${ }^{10}$ Iberico Ruiz 2016.
} 
catolicismo desde medios modernos como las sociedades, la prensa y la participación en la esfera pública. En 1867, en Lima se constituyó la Sociedad Católico-Peruana por iniciativa del obispo Teodoro del Valle, cuya finalidad era defender como "católicos soldados» la religión de sus enemigos. ${ }^{11}$ Sin embargo, en el Perú la militancia laical se afianzará en el periodo posterior a la guerra con Chile, con la fundación de la Unión Católica del Perú en Arequipa en 1886.

La militancia laical peruana coincidió con un cambio en el escenario político-teológico en el catolicismo occidental. León XIII (1878-1903) reconoció que, a pesar del error, la noción de la soberanía popular se podía reconocer como válida al igual que todo el sistema político surgido de los valores políticos modernos. ${ }^{12}$ Dos encíclicas fueron fundamentales para abrir la posibilidad de diálogo y negociación con el mundo moderno. En 1891, la encíclica Rerum novarum permitió la formación de sociedades católicas de trabajadores que a la larga fueron espacios de politización para los obreros y artesanos. Igualmente, la encíclica Graves de communi re de 1901 usó por primera vez en el magisterio papal el término «democracia cristiana", como reconocimiento de las ideas de justicia, del derecho a la propiedad y la preocupación política por los desfavorecidos. ${ }^{13}$ Por ello, la apertura de León XIII implicó un reacomodo de la relación de la militancia católica con la sociedad y la política. Igualmente, el pontífice, conocido como el «Papa obrero» por su promoción del «catolicismo social», abrió todo un escenario de involucramiento de los católicos en el devenir de la sociedad. ${ }^{14}$ Los invitó a tomar parte activa en la redefinición de la sociedad, acorde a los valores morales del catolicismo.

La historia del catolicismo en Arequipa se enmarca en estos procesos de redefinición del catolicismo. En Arequipa, los obispos Juan Ambrosio Huerta (1880-1897), Manuel Segundo Ballón (1898-1905)

${ }^{11}$ Klaiber 1988: 102-103. Un proceso similar se observa en otros países de la región. En 1868 en México, los laicos se organizaron en la Sociedad Católica de México, para promover la fe en la esfera pública la fe (Lynch 2012: 195-196).

${ }^{12}$ Chadwick 1998: 294-304.

13 Ib.: 320-322.

${ }^{14}$ Cárdenas 2018:159-160. 
y Mariano Holguín (1906-1945) cumplieron el papel de orientar las prioridades políticas, pastorales y sociales de la Iglesia local. ${ }^{15}$ Ellos se hicieron eco de las preocupaciones teológico-políticas de Roma en relación con el contexto sociopolítico de Arequipa. Además, el gobierno de los obispos reflejó el cambio de actitud de los pontificados en relación al mundo moderno y la necesidad de negociar con él.

Se podría establecer un primer momento episcopal (1880-1905), durante los gobiernos de Huerta y Ballón, caracterizado por el lenguaje pontificio radicalmente ultramontano y una pastoral apologética e intransigente. Un segundo momento corresponde con el gobierno episcopal de Holguín, quien siguiendo a León XIII y sin dejar el discurso apologético, permitió iniciativas católicas sociales y abiertas al diálogo con algunos elementos de la modernidad. Incluso, promovió el Partido Católico y la participación laical en la política como medio para discutir la validez del catolicismo en la formación del estado y la sociedad. Monseñor Holguín representaba la paradoja católica respecto de la modernidad, entre el rechazo y la negociación. Rechazo de la emergencia de nuevos actores y negociación de espacio para la Iglesia en la esfera pública sociopolítica. De esta manera, la historia de la militancia laical en Arequipa muestra la complejidad del proceso de resurgimiento católico, las transformaciones del discurso católico y el involucramiento en la esfera social y pública.

\section{LA «CAUSA CATÓLICA», LA MONOPOLIZACIÓN POLÍTICA Y LA MILITANCIA} LAICAL: LA UNIÓN CATÓLICA DE AREQUIPA (I 886-I905)

La fundación de la Unión Católica de Arequipa (UCA) estuvo ligada a la "causa católica» producida por la campaña contra los jesuitas y que culminó con su expulsión por el parlamento peruano en octubre de 1886. ${ }^{16} \mathrm{La}$ "causa católica» movilizó a los laicos a organizarse

${ }^{15}$ Para un estudio sobre los obispos y su relación con el ultramontanismo y la modernización de Arequipa, véase Iberico Ruiz 2020.

${ }^{16}$ La expulsión fue provocada por el conflicto en torno al libro Compendio de Historia del Perú del jesuita Ricardo Cappa, profesor del colegio La Inmaculada en Lima. Cappa exaltó la labor de España en América y disminuyó el papel cumplido por los peruanos en la independencia. Los jesuitas retornaron al país un año después (Klaiber 1988: 111). 
en una sociedad para defender los intereses de la Iglesia frente a las pretensiones de sus enemigos. Si bien la primera reunión nacional para lanzar una sociedad apologético-política se realizó en el Teatro Politeama de Lima en octubre de ese mismo año, el presidente de la Unión Católica de Arequipa (UCA), Carlos Elías, destacó que fue en Arequipa donde se «tomó la iniciativa de promover [...] el establecimiento de un centro católico». ${ }^{17} \mathrm{La}$ iniciativa de organizar una sociedad de carácter nacional surgió de la UCA, que encargó a Mariano Belaunde y Manuel Bustamante la organización de la sociedad a nivel nacional. El primer Consejo Directivo de la UCA de Arequipa de 1887 estuvo integrada por diecisiete miembros. La componían miembros de las clases altas y de los sectores profesionales y artesanos de la ciudad. ${ }^{18}$

El apoyo de Juan Ambrosio Huerta, obispo de Arequipa, fue crucial para el inicio de la UCA, pues en ella el prelado reconocía la concreción de los Círculos Católicos, sociedades laicales promovidas por Pio IX y León XIII para enfrentar el avance del liberalismo y la masonería. El prelado impuso una lectura apologética a la misión de la UCA. Huerta les dedicó una carta pastoral, en la que recomendaba la lectura del capítulo 24 del evangelio según san $\mathrm{Mateo}^{19}$ para tomar consciencia del momento de persecución que vivían los católicos y la necesidad de mantenerse perseverantes en defensa de la fe. ${ }^{20}$ En esta pastoral, Huerta definió como objetivo de la Unión Católica la defensa del catolicismo contra el liberalismo y la masonería. El obispo exigía a los laicos de la UCA la participación en política: «¿con qué derecho podría reprocharse

17 Citado en García Jordán 1991: 320.

${ }^{18}$ El consejo estaba formado por el presidente Juan Manuel López de Romańa y el vicepresidente, Enrique Marcó del Pont; los vocales José de la Fuente, Melchor J. Bedoya, J. Casimiro Valdez, Manuel Aguirre, José Santos Talavera, Daniel E. Villalonga, Santiago Vargas, Benjamín Angulo, José A. Vivanco, Alejandro López de Romaña, Mariano A. de Belaunde, Elías Soto Marina e Isaac Cáceres Vargas. Finalmente, los secretarios eran Manuel T. Marina y Manuel Bustamante y Barreda (Unión Católica de Arequipa 1887: 14).

${ }^{19}$ El capítulo 24 del evangelio de san Mateo detalla en clave escatológica los padecimientos que los discípulos de Jesús sufrirán el tiempo previo a su segunda venida para juzgar a la humanidad.

${ }^{20}$ Huerta 1886: 3-4. 
a los católicos, tan ciudadanos como los que mas, que asociados para trabajar en la defensa de los principios del Catolicismo en todo orden, se ocupen de la política?». ${ }^{21}$

Para Huerta, la política no era un asunto externo a la fe. Se debía hacer política como católicos y ciudadanos para que se afianzase un estado y una sociedad sobre la base de los principios de la moral y la religión, y así hacer frente a las reformas seculares que amenazaban restringir el espacio público para la Iglesia. ${ }^{22}$ La preocupación del prelado se daba en el marco de la expulsión de los jesuitas por la presión liberal, que identificaba como limeña, y la tentativa de reformas liberales como parte del proceso de reconstrucción nacional luego de la guerra con Chile. Después de la guerra con Chile, el gobierno central, dirigido por Andrés Avelino Cáceres, había articulado un modelo republicano-autoritario con el soporte ideológico de liberales y positivistas reformistas que atemorizaban a los sectores católicos. ${ }^{23}$ En este trabajo de defensa, Huerta reconocía la importancia del laicado y la necesidad del trabajo conjunto con la jerarquía para construir una nueva sociedad y defender la fe católica. ${ }^{24}$

En respuesta al prelado y a la coyuntura, la UCA inmediatamente inició actividades. En noviembre de 1886, la sociedad recogió más de diez mil firmas en un acta de apoyo a la Compañía de Jesús. ${ }^{25}$ Era la primera muestra de la capacidad de convocatoria y de la canalización pública del sentimiento católico a favor de la Iglesia. Sin embargo, el acta, enviada al parlamento, no logró detener la expulsión de los jesuitas. En Arequipa, la situación se complicó el 19 de enero de 1887. Ese día, reunidos en el Palacio Episcopal de Arequipa, se encontraban el consejo directivo de la UCA, algunas laicas y laicos, miembros del clero y tres sacerdotes jesuitas que preparaban un nuevo pedido a favor de la permanencia de los jesuitas. Alrededor de las nueve de la noche, irrumpieron las autoridades policiales en la residencia — tras derribar la puerta — para llevarse a los

\footnotetext{
${ }^{21}$ Ib.: 5 .

${ }^{22}$ Ib.: 7-8.

${ }^{23}$ McEvoy 2017: 229-232, 261-265.

${ }^{24}$ Huerta 1886: 8.

${ }^{25}$ Garreaud Indacochea 2015, II: 38.
} 
jesuitas al exilio. Recorrieron el Palacio Episcopal, incluida la capilla y el cuarto de estudio del prelado, de manera tal que «los ministros de las tinieblas parodiaron tristemente la escena del Huerto de los Olivos». ${ }^{26}$ Luego de encontrar a los jesuitas, fueron apresados y expulsados a La Paz. La situación descrita en un claro lenguaje bíblico-apocalíptico señalaba la sensación de persecución que los católicos vivían ante la amenaza liberal-masónica. Como Jesús de Nazaret, ellos — clérigos y laicos- eran perseguidos por los agentes del mal en el Perú.

La sensación de persecución se afianzó con un incidente en la Iglesia del pueblo de Quequeña, a unos veinticinco kilómetros de Arequipa. El gobernador de Arequipa, el comandante Romero, junto a su familia y a Tomás Málaga Torres llegaron al pueblo de Quequeña, donde fueron invitados a los oficios litúrgicos en la parroquia. El joven Málaga permaneció con sombrero durante los oficios religiosos y la procesión. A pesar de la solicitud del inspector de la policía, se negó a quitárselo, y, muy al contrario, lo amenazó con un revolver. La situación provocó la exaltación de la población, cuyo único afán era quitarle el sombrero por la irreverencia del gesto. El comandante Romero amenazó con encarcelar a los pobladores, "agregando que en Arequipa no había tal Catolicismo», y denunció a la Unión Católica de Quequeña de instigar una rebelión contra el Supremo Gobierno. ${ }^{27}$

Este sentimiento político reafirmó entre los miembros de la UCA la necesidad de conquistar el espectro político para defender y propagar «los principios y obras católicas» y defender «la libertad y derechos de la Iglesia» en «la vida pública». ${ }^{28}$ En sus primeros estatutos, los miembros de la UCA señalaron que su labor política era

cristianizar [...] a los gobiernos y a los pueblos, de trabajar porque los Congresos den leyes justas y convenientes con las cuales se procure el adelante del país, sin provocar conflictos, considerando siempre el progreso material no como fin sino como medio de alcanzar la perfección moral; de influir en

${ }^{26}$ Unión Católica de Arequipa 1887: 7-8. Sobre el lenguaje apocalíptico del catolicismo decimonónico, véase Cid 2014.

${ }^{27}$ Ib.: $12-13$.

28 Ib.: $3-4$. 
el ánimo del Jefe del Estado y de sus Ministros para que en todos los ramos de la administración impere la doctrina católica. ${ }^{29}$

La política, considerada como "provechosa» por León XIII en Immortale Dei (1885), era considerada una exigencia para los católicos. Desde la óptica de la UCA, «cristianizar» la política implicaba volver católicas las instituciones como el Congreso y el ejecutivo, de manera que fueran promotoras de la doctrina católica. No bastaba ya la confesionalidad legal del Estado. En este sentido, la propuesta era construir una sociedad católica, pues «la política no es, ni puede ser otra cosa que el gobierno de los pueblos con sujeción a los principios de la ley evangélica», de manera tal que «las doctrinas de la Iglesia sean para los pueblos lo que es la sangre para el cuerpo». ${ }^{30}$ La política no era un medio de disputa para proyectos políticos, sino un escenario para monopolizar la acción desde la racionalidad católica. A través de esta concepción de la política, se buscaba implementar un proyecto cristiano sobre el estado y la sociedad. La política se entendía como la manera de moldear católicamente al estado. La tarea de finales del siglo XIX era recuperar para Cristo y la Iglesia el sistema político moderno y evitar su caída en el liberalismo y la masonería. A esta labor política se enfrascaron los miembros de la UCA en un escenario que consideraron hostil.

En el Perú de la Reconstrucción (1885-1895), se afianzó un espíritu reformista con miras a modernizar mediante «leyes progresistas» las estructuras del país. Las leyes estaban inspiradas por las tendencias liberales y positivistas de los miembros del gobierno. Prueba de ello era que en los partidos Civil, Demócrata y Constitucional se encontraban grupos liberales, antirreligiosas y anticlericales que se volvieron en activos promotores de la modernización del país. ${ }^{31}$ Un ejemplo de las nuevas orientaciones políticas fue el programa anticlerical del partido Unión Nacional de 1891 que defendía la necesidad de «laicalizar el estado, estableciendo libertad de cultos, el matrimonio y el cementerio civiles, la

\footnotetext{
${ }^{29} \mathrm{Ib}$.

${ }^{30}$ Ib.: 5 .

${ }^{31}$ Armas Asín 1998: 116.
} 
escuela neutral y todas las reformas que se reclama el espíritu del siglo». ${ }^{32}$ La secularización del estado fue una de las prioridades del régimen.

Durante el denominado periodo de la República aristocrática (18951919), el discurso modernizador se profundizó. De esta manera, bajo la égida del Partido Civil, se modelaron políticas públicas que buscaron transformar social y culturalmente el país. Los esfuerzos se concentraron fundamentalmente en Lima. ${ }^{33}$ El proyecto civilista se concretizó en leyes como la del matrimonio civil, la laicización de los cementerios, la tolerancia y la libertad de cultos y la expropiación de bienes eclesiales. ${ }^{34}$ Las leyes buscaban atraer mayor migración extranjera, fundamentalmente de países protestantes, y consolidar la imagen de un país moderno. Por ello, se puso en la agenda política la tolerancia y libertad de cultos como signos de una nueva relación con la migración y la práctica religiosa en el país. ${ }^{35}$ Ambas propuestas amenazaban, desde la perspectiva católica, la unidad nacional.

En este periodo, la UCA mantuvo una actitud apologética en la lógica de mantener la confesionalidad del estado y «cristianizar» el estado y la sociedad. Algunos eventos dan cuenta de este propósito. En 1889, los miembros de la UCA participaron de una campańa, organizada por la diócesis contra el informe de Guillermo Seoane, ministro de Justicia, Instrucción y Culto, sobre la necesidad implementar el matrimonio laico para facilitar la inmigración extranjera. La campańa criticaba la postura del gobierno de conceder el «matrimonio laico» para "el inmigrante que trae distintas creencias», en lugar de respetar «la veneranda religión de nuestros padres católicos». ${ }^{36}$ Como parte de la protesta pública, se difundió un folleto, a «espensas de la Unión Católica». El documento contenía el resumen de las actividades realizadas contra la propuesta de Seoane, donde se destacaba la fidelidad de Arequipa como resguardo de

\footnotetext{
32 Ib. 117.

${ }^{33}$ Espinoza 2015: 99-100.

${ }^{34}$ García Jordán 1988 y 1991; Armas Asín 1998.

35 Fonseca 2003: 216; García Jordán 1988: 73.

${ }^{36}$ Citado en García Jordán 1988: 69.
} 
la catolicidad del país frente Lima. ${ }^{37}$ Para la ocasión, se realizó un triduo entre el 3 y el 5 de octubre de 1889 con la asistencia de "personas de todas las clases sociales» de la ciudad y "ha sido la primera en esta vez como en otras, en levantar su voz contra el error y la impiedad». ${ }^{38}$

En noviembre de 1895, la discusión en el Senado de la ley de administración estatal de los bienes conventuales produjo una nueva reacción de la UCA. Se organizaron para preparar y enviar una serie de cables a senadores opositores a la ley. En ellos, solicitaban detener la discusión en la Cámara alta para «calmar la excitación» en Lima. ${ }^{39}$ En Arequipa, se sumaron a las iniciativas coordinadas por el arzobispo de Lima, Manuel Bandini, y lograron incorporar a otros obispados y sociedades católicas del país. La presión nacional logró que la ley no fuera considerada en el debate y mostraron la fuerza de los sectores católicos en la política nacional. ${ }^{40} \mathrm{Al}$ año siguiente, el 23 de diciembre de 1896 , el presidente de la república Nicolás de Piérola promulgó la ley del matrimonio civil que produjo la renuncia del jefe del gabinete Alejandro López de Romaña, hijo del presidente de la UCA. El motivo era que la nueva norma atentaba contra sus principios religiosos. ${ }^{41}$

Las normativas secularizadoras dieron motivo para que, en noviembre de 1896, se celebrase el Primer Congreso Católico, bajo la presidencia honorario del arzobispo de Lima y la vicepresidencia del obispo de Arequipa. Los trescientos delegados, entre hombres y mujeres, se reunieron en la iglesia de San Francisco en Lima. La UCA nombró delegados a Abraham de Vinatea y a Mariano Belaúnde. Este último ocupó una de las vicepresidencias de la comisión organizadora del congreso y presidió la comisión de prensa y propaganda católica. Además, asistió el arequipeño Pedro José Rada, joven político y miembro del Círculo de la Juventud Católica, una asociación vinculada a la UCA.

\footnotetext{
37 Garreaud Indacochea 2015, II: 41.

38 Ib.: 41-43.

${ }^{39}$ Bandini 1895: 71-73.

${ }^{40}$ En 1901, se aprobó una ley que reconocía los bienes conventuales como privados (Armas 2005: 12).

${ }^{41}$ Garreaud Indacochea 2015, II: 44.
} 
Mariano Belaúnde fue invitado a dar uno de los discursos en el congreso, donde expresó la preocupación por la necesidad de educar a los jóvenes en la moral católica y formar asociaciones «de un ángulo a otro del Perú» para frenar los ataques contra la religión. Con ello, se lograría «acometer la regeneración de la Patria; y entonces y sólo entonces entrará majestuoso el Perú en los dilatados horizontes del progreso». ${ }^{42}$ En la misma línea, Rada estableció la relación entre el progreso y el avance regenerador del catolicismo en el Perú, por lo que se oponía al positivismo y las nuevas doctrinas filosóficas, con presencia activa en la escena política e intelectual limeña. Dichas doctrinas desconocían el aporte del catolicismo al progreso del país. Por ello, la juventud debía formarse bajo la religión católica para consolidar la civilización católica en el Perú. ${ }^{43}$ Ambos laicos arequipeńos destacaron abiertamente no solo la compatibilidad entre el progreso y el catolicismo, sino la centralidad de la fe para un auténtico progreso nacional.

$\mathrm{Al}$ iniciar el nuevo siglo, la Unión Católica de señores inició un proceso de reforma a solicitud del nuevo obispo Ballón. ${ }^{44}$ El prelado se reunió con los miembros de la UCA en su palacio para reforzar el papel apologético de la sociedad contra «los ataques que los enemigos de la religión hacen a las creencias católicas y a la piedad de este pueblo». Igualmente, se encargó al nuevo directorio "ganar terreno como el centinela avanzando y cuida y vela por el catolicismo de Arequipa». ${ }^{45}$ El nuevo presidente designado fue Mariano Belaunde, entonces ministro de Hacienda de Eduardo López de Romańa, presidente de la república. ${ }^{46}$ La propuesta de reforma de Ballón se daba en el contexto de la consolidación de grupos liberales en

\footnotetext{
42 Congreso Católico del Perú 1897: 107-108.

43 Ib.: 261-265.

${ }^{44}$ En su carta de toma de la diócesis, señalaba que la misión «importantísima» de la Unión Católica y otras sociedades piadosas «nos dan derecho para esperar, con la más íntima convicción, de que, llenas de celo, defenderán siempre los dogmas sagrados de nuestra augusta religión, darán gloria a Dios» (Ballón 1898: 23). Para el prelado, las asociaciones laicales tenían un claro objetivo apologético.

${ }^{45}$ El Deber, 8-VIII-1900: 2. Consultado en la biblioteca del convento de la Recoleta en Arequipa.

${ }^{46}$ Garreaud Indacochea 2015, II: 46.
} 
Arequipa, que eran abiertamente críticos del poder económico e ideológico del catolicismo en la ciudad y, además, cercanos a los protestantes. El prelado consideraba como fundamental la apuesta apologética de la UCA. En este sentido, se mantuvo en la línea tradicional de Huerta, de «cristianizar» la política desde la perspectiva católica.

Ballón no comprendió que los cambios en Arequipa podían generar un nuevo escenario para la acción pública del catolicismo. Pronto, la ciudad se vio sacudida por la presencia de liberales, anarquistas y socialistas. El principal protagonista de este ciclo fue el Partido Liberal Independiente. La actividad del prelado se enfocó en oponerse a las nuevas ideas y al Partido Liberal. En abril de 1901, Ballón publicó la encíclica de León XIII sobre la democracia cristiana, Graves de communi re (18 de enero de 1901), con una breve introducción. En ella, destacaba los «errores socialistas que, desgraciadamente, cubren el mundo amenazando su ruina, y permite a los hombres ver los escollos y peligros que le amenazan en la vida social». ${ }^{47} \mathrm{La}$ interpretación del prelado no reflejaba la compleja y ambigua línea trazada por León XIII sobre el reconocimiento del sistema político democrático y la necesidad de la participación política de los laicos en dicho sistema. ${ }^{48}$ Muy por el contrario, para Ballón la encíclica ratificaba su oposición a las ideas liberales, interpretadas como socialistas, y su idea de la exclusiva validez del catolicismo como articulador social del país.

Los liberales Francisco Mostajo, Lino Urquieta, Modesto Málaga, Alberto Campos, Francisco Chiquiwanca Ayulo y Alejandro Docarmo fueron los protagonistas de la crítica contra la Iglesia en Arequipa. Los liberales eran críticos del empobrecimiento y las condiciones de vida de los sectores marginales de la ciudad, consecuencia del crecimiento comercial y la progresiva consolidación de la elite y la burguesía. ${ }^{49}$ Estos

${ }^{47}$ Ballón 1901: 3-4. En otras diócesis iberoamericanas, también se realizó una interpretación apologética de los documentos de León XIII. Un ejemplo fue el obispo de Zamora (España), Luis Felipe Ortiz, quien dedicó en su casi totalidad la presentación de la encíclica papal a condenar el socialismo y sus consecuencias nocivas en la sociedad (Hernández 2016: 224).

${ }^{48}$ Chadwick 1998: 320-322.

${ }^{49}$ Carpio Muñoz 1990: 550. 
liberares tenían una profunda consciencia social crítica de las causas de la miseria de Arequipa. En El Ariete, hablaban de la nueva esclavitud del obrero impuesta por el capitalista. Criticaban a «las clases acomodadas» que «hacen alarde también de ser poseedores de una supremacía moral que ni siquiera comprenden». ${ }^{50}$ Su crítica se extendió a la contradicción entre la fe católica de muchos miembros de la élite y los estilos de vida. No obstante, no se consideraban como anticlericales y laicistas, sino como crítico de la pasividad eclesial frente a la cuestión social. Sobre el tema, Modesto Málaga seńalaba que ellos eran

enemigos del clericalismo apóstata de ese clericalismo que en vez de ceñir sus actos a las doctrinas de la religión, los ciñe a sus bajas pasiones y a sus encendidos odios; de ese clericalismo que en lugar de ser redentor es verdugo, que en lugar de ser reflejo de caridad y de mansedumbre, es retrato de avaricia, de soberbia, de lujuria, de odio; somos enemigos de ese clericalismo inquisidor que cree ver en cada libertad a una enemiga del cielo; que cree ver en el progreso un reflejo del infierno; que cree ver en cada conciencia libre una rebelión, y en cada derecho individual una anarquía. ${ }^{51}$

La oposición liberal adquirió notoriedad el 9 de abril de 1905, cuando se realizó su primer mitin en la plaza de Armas de Arequipa. Se reunieron para solicitar a las autoridades el cumplimiento de la resolución del gobierno central de tomar el palacio episcopal del Buen Retiro para volverlo un lazareto provisional, ante la crisis de salud desatada por peste bubónica en Mollendo y Arequipa. ${ }^{52}$ La negativa de ceder el palacio episcopal por parte del prelado colisionó con la presión de los liberales favorecidos por el prefecto Fernando Alvizuri, quien fue denunciado en El Deber como alguien guiado y agradecido con los liberales. ${ }^{53}$ Los

\footnotetext{
${ }^{50}$ Discurso de Lino Urquieta (El Ariete, año 1, no 3). Citado en Carpio 1990: 550.

${ }^{51}$ Discurso de Modesto Málaga (El Ariete, 17-IV-1902). Citado en Carpio 1990: 549. ${ }^{52}$ Ballón 2001: 159.

${ }^{53}$ El Deber, 13-IV-1905: 2. En los cablegramas se denunciaba ante Carlos Elías que uno de los organizadores del mitin, Chávez Bedoya, apareció por la ventana de la prefectura con el prefecto Alvizuri. Los otros organizadores fueron Frisancho y Mostajo. Además, un obrero de apellido Goizueta se dirigió a Alvizuri para solicitarle tomar el Buen Retiro y la supresión del artículo 4 de la Constitución en Arequipa, sobre la exclusividad del culto católico.
} 
laicos de la UCA intentaron crear un ambiente crítico contra los liberales apelando influenciar en el gobierno central mediante el envío de telegramas al presidente de la Unión Católica de Lima, Carlos Elías. En ellos, denunciaron la asociación de los liberales con el prefecto. Adicionalmente, El Deber denunció que el verdadero objetivo del mitin era sido «insultar públicamente al Iltmo. Obispo y hacer escarnio de la Religión que el Estado garantiza». ${ }^{54}$ No obstante, a pesar de las denuncias de $E l$ Deber y la presión de los laicos de la UCA, los liberales consiguieron que se tomara el Buen Retiro con el uso de la fuerza pública. La situación se hizo insostenible para el prelado, pues quedó desprestigiado, desautorizado, y cargó con el peso de su falta de caridad por negarse a convertir su palacio episcopal en un lazareto, en plena crisis de salud. En consecuencia, Ballón se vio obligado a renunciar al obispado de Arequipa en carta a Pio X. ${ }^{55}$

La renuncia de Ballón al obispado de Arequipa mostró la fuerza movilizadora de los nuevos grupos políticos y la importancia de la crítica social argüida por ellos. Adicionalmente, el triunfo político de los liberales fortaleció los lazos con los protestantes, promotores de la libertad de cultos, y el creciente mundo laboral en Arequipa. Prueba de ello fue que, en 1907, en el periódico La Bandera Roja, los protestantes manifestaron públicamente su complacencia con el mundo obrero en los siguientes términos:

Si la clase obrera abraza el cristianismo, abandonando el catolicismo, oirán la palabra de Cristo que les dice: «La verdad os hará libres [...]. Sin duda, para disfrutar de esta libertad propia de los hijos de Dios, deben alentar en el corazón obrero la moral, el amor de Dios y el espíritu fraternal cristiano». ${ }^{56}$

${ }^{54}$ El Deber, 11-IV-1905: 2.

${ }^{55}$ Ballón 2001: 164. En carta del 9 de abril, el obispo informó al prefecto de la imposibilidad de entregar el Buen Retiro por cuestiones de salubridad, pues «se pone en inminente peligro de contagio al Monasterio de Santa Rosa, al Colegio Salesiano, a la importante población de San Antonio, a la Ranchería y en consecuencia a toda la ciudad" (El Deber 12-IV-1905: 2). El 10 de abril, los miembros de la Unión Católica y otros señores de la ciudad firmaron un Acta de desagravio por los insultos contra el obispo (El Deber, 14-IV-1905: 2).

${ }^{56}$ Fonseca 2002: 113. 
La caída del obispo Ballón mostró la crisis de la perspectiva pública católica en clave apologética y monopolizadora. El marco legal de exclusividad católica mostraba sus grietas en el escenario de crecimiento de la pluralidad social y política del país y de Arequipa. La esfera pública parecía estar exclusivamente tomada por los nuevos grupos políticos y los católicos necesitaban moverse de nuevas maneras. La Unión Católica no había logrado posicionarse más allá del discurso apologético de defensa de la fe ni articular una alternativa política en el nuevo escenario de emergencia del pluralismo de opciones políticas de la ciudad. Las proclamas y actas, el uso de la prensa y la apelación a la autoridad civil no bastaban para monopolizar la política. Era necesaria una manera nueva de entender la esfera pública y de moverse en ella en las claves del cambio sociopolítico de inicios del siglo XX.

\section{EL CATOLICISMO SOCIAL Y EL FALLIDO INTENTO DE UN PARTIDO CATÓLICO EN AREQUIPA (I907-I9I9)}

En 1906, la Santa Sede designó a Mariano Holguín como obispo de Arequipa. Su llegada a la sede episcopal implicó un cambio en la manera de enfrentar la nueva realidad de cambio social y política de Arequipa. Ese mismo año, Holguín inició un proceso de reestructuración de la UCA. Del mismo modo, consideró fundamental la apertura de los registros de inscripción para todo varón arequipeño dispuesto a vincularse en la defensa de su fe. ${ }^{57}$ En paralelo, el obispo fortaleció las sociedades de atención caritativa y promovió el Círculo de Obreros Católicos como medios para acrecentar la presencia de la Iglesia. En este proceso, el prelado se propuso fortalecer el papel de los laicos e incentivar su participación pública, no solo apologética, sino social y política para enfrentar las críticas de los liberales, el avance protestante y la «cuestión social». El catolicismo apologético-social propugnado por Holguín fue asumido activamente por la rama femenina de la UCA y el Círculo de Obreros Católicos, mientras que el activismo público y político tuvo su cenit y fracaso con la fundación del Partido Católico. A través del catolicismo 
apologético-social y político, se buscó proponer un modelo de sociedad para el país, regido por valores morales que promoviesen el ansiado progreso del país.

El catolicismo apologético-social como proyecto para país: de la UCA de señoras al Círculo de Obreros Católicos (COC)

La UCA de señoras organizó su labor fundamentalmente en el sostenimiento de obras a favor de las iglesias pobres, de la educación religiosa en las parroquias de la ciudad, de la promoción del matrimonio religioso y de la defensa de la moralidad de la prensa. Las obras gestionadas por la UCA de señoras eran la Obra de los Tabernáculos, las Escuelas dominicales, la Obra de San Francisco Regis y el Apostolado de la prensa. Las actividades del grupo les permitieron asumir roles activos en la vida pública de la ciudad y en la vida eclesial. Cada una de las obras buscaban implementar un modelo social moral para Arequipa, como ciudad organizada por valores católicos. Como programas de asistencia, las obras de la UCA se insertaban en el programa modernizador de la República aristocrática y buscaban no colisionar con el proceso, sino fortalecerlo mediante la moral católica. Por medio de la actividad asistencial, las señoras de la UCA pusieron como valores centrales de la configuración social moderna al matrimonio religioso, amenazado por el matrimonio civil y el divorcio, y el papel de la mujer en la familia como madre, educadora y defensora de la fe. Ellas trasmitían la nueva sensibilidad católica del cambio del siglo, en el cual las mujeres eran agentes fundamentales para la trasmisión de la fe católica.

La Obra de San Francisco de Regis defendía la institución de la familia, amenazada por las reformas legales a favor del matrimonio civil y el divorcio. A través de esta asociación, se promovieron matrimonios religiosos entre parejas de convivientes de Arequipa, en diversas parroquias de la ciudad. La defensa de la familia se convirtió en un componente central de la moral y la doctrina católica desde fines del siglo XIX. En tiempo del obispo Huerta, señalaba que la destrucción de la sacralidad del origen de la sociedad, la familia, también era destruir el orden social 
que perjudicaría a la mujer. ${ }^{58}$ Por ello, como parte de su trabajo, las señoras visitaban familias en situación de cohabitación para promover la importancia social y moral del matrimonio católico. De esta manera, entre 1908 y 1924, las señoras de la UCA lograron aproximadamente 604 matrimonios religiosos de parejas en uniones ilegítimas, 19 bautizos y 1828 visitas a diversos hogares para informar sobre la importancia del matrimonio religioso. ${ }^{59}$ Es decir, casi un tercio de las visitas se concretaron en un matrimonio religioso.

La preocupación por el matrimonio católico y la moral familiar se extendió hacia la moral de la sociedad. Para ello, las señoras de la UCA promovieron dos asociaciones: el Apostolado de la Prensa y la Liga contra Espectáculos Inmorales. El Apostolado se encargaba de censurar las publicaciones periódicas, folletos, libros y material gráfico que atentase contra la moral, la familia y la doctrina católica. Entre 1908 y 1924, el Apostolado canjeó y quemó alrededor de 10997 libros, folletos y estampas. La labor inquisitorial no culminaba con la expurgación del material inmoral, pues las señoras también repartían hojas sueltas, promovían colecciones de libros como el Buen combate y Biblioteca ligera, y donaron libros para los enfermos del hospital Goyeneche y los centros de obreros. En las mismas fechas, el material repartido sumó un aproximado de 16818 libros, hojas sueltas y folletos. ${ }^{60}$ La defensa de la fe parecía estar garantizada, por lo menos en la cultura escrita. Por su parte la Liga, organizada por el obispo Holguín en 1914, tenía como finalidad la oposición pública y legal a los espectáculos opuestos a las buenas costumbres, la piedad cristiana, las obscenidades, las injurias contra el clero, el matrimonio y la familia, el amor libre y el elogio del suicidio. ${ }^{61}$

Las obras apologético-sociales de las señoras y señoritas de la UCA estuvieron acorde con el modelo de mujer católica y «apóstol», encargada

${ }^{58}$ García Jordán 1988: 70.

${ }^{59}$ Datos recogidos de las Memorias de la UCA de Señoras entre 1908 y 1924, con excepción de los años de 1915, 1916, 1917, 1919 y 1922, cuyas memorias no fueron ubicadas.

${ }^{60}$ Ver nota 62.

${ }^{61}$ Liga contra Espectáculos Inmorales 1914: 10-11. 
no solo del hogar y los hijos, sino de conservar las «buenas costumbres» y la moral católica en la esfera pública. Como afirmaba un folleto de presentación de la Liga, la mujer podía ser o como Eva o como María, «la una, apóstol de la serpiente; la otra, apóstol de Dios». ${ }^{62}$ Todo dependía del lugar en el que se ubicaba. Para hacerse similar a María, debía estar del lado de la familia, la moral y la Iglesia. Esta defensa era tanto al interior de la casa como en la esfera pública. En paralelo a esta imagen femenina del catolicismo, en Arequipa, la Iglesia favoreció la creación de un grupo obrero, el Círculo de Obreros Católicos (COC) como forma de generar una cultura obrera católica y una imagen adecuada del trabajador católico.

En 1896, el entonces fraile franciscano Mariano Holguín fundó el Círculo de Obreros Católicos (COC) como una sociedad para promover la restauración cristiana de los obreros y, con ello, colaborar con la reconstrucción del Perú. ${ }^{63}$ El COC buscaba restaurar la catolicidad de la vida obrera a través de la educación de los trabajadores, la creación de una sección de socorros mutuos, de espacios de recreación y de lectura para sus socios. ${ }^{64}$ Como lugar de socialización, el COC hizo hincapié en valores religiosos, conducta moral y valores cívicos que todo miembro de la sociedad debía cultivar y vivir. ${ }^{65}$ En la línea con Holguín, el COC realizó una adaptación progresiva al catolicismo social que buscaba moldear la sociedad de acuerdo con los valores cristianos. En octubre de 1914, se celebró una velada en honor de los obreros organizada por un grupo de señoras de la Liga. Se dio inicio a la reunión entonando el "Himno al Obrero», cuya letra equiparaba el trabajo a una plegaria a Dios: «Del obrero la plegaria / Cuan benigno acoje Dios / Cuando al ir a su trabajo / La dirige con fervor». Asimismo, el trabajo cristiano contribuía una sociedad armónica: «Tenga el rico sus riquezas / Mande el fuerte sin rival / Yo prefiero del obrero / La risueña y dulce paz». ${ }^{66}$ Con

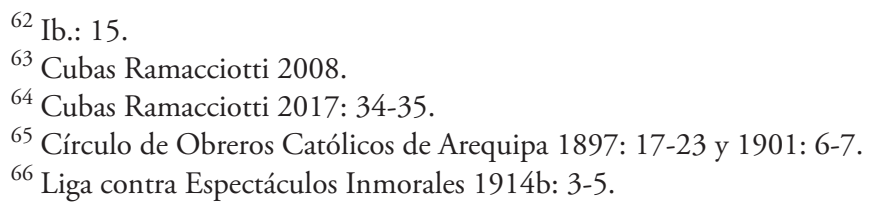


ello, el obrero católico era un garante de la armonía de la sociedad que, a su vez, reconocía la importancia del trabajador católico «en la marcha de las sociedades modernas». ${ }^{67}$

La velada concluyó con el discurso de Holguín quien enfatizó que en el obrero «le ha parecido ver la imagen palpitante del divino Obrero de Nazareth». La conexión entre el Nazareno y el obrero se oponían, en palabras de Holguín, a la "secta socialista» que «atiza en el noble corazón del obrero las terribles pasiones de la envidia, del odio contra el capitalismo, contra el rico». Para Holguín, la caridad cristiana — ejercida por las damas de la Liga - era signo de «que la distinción de clases no es una barrera para la fraternidad cristiana, que hace de todas, una sola gran familia». ${ }^{68}$ De esta manera, el catolicismo social de Holguín desplegado a través de las organizaciones laicales era promotor de una cultura política católica a favor de la armonía social. En el caso del obrero, este debía reconocer cuál era su lugar y orden en la promoción del progreso de la sociedad moderna. El discurso y la praxis del catolicismo social eran una alternativa a la crítica del orden socio-político del socialismo y el liberalismo.

No obstante, la rigidez política del discurso de la COC, en enero de 1915, en el marco de protestas contra nuevos impuestos promovidos por el gobierno de Benavides, la instó a involucrarse en el «Comité Central de Defensa contra los nuevos impuestos». En una manifestación del 30 de enero que le costó la vida a nueve personas, el periódico de la UCA, El Deber, denunció el acto como un atropello contra el derecho ciudadano a la protesta. ${ }^{69}$ Si bien León XIII descalificó como inmorales a las huelgas y manifestaciones, teólogos como el jesuita alemán August Lehmkuhl consideraban, ya en 1899, que bajo ciertas circunstancias, la huelga era moralmente aceptable. ${ }^{70}$ La manifestación de enero mostró la compleja relación de la doctrina social católica con la protesta, pues los trabajadores católicos entraron en la lucha política y ciudadana por derechos sociales.

${ }^{67} \mathrm{Ib}$.

${ }^{68}$ Holguín 1914b: 24-25.

${ }^{69}$ El Deber, 31 de enero de 1915: 2.

${ }^{70}$ Chadwick 1998: 316-317; Cubas Ramacciotti 2017: 32. 
Tras la Primera Guerra Mundial, la economía se resintió y el gobierno de José Pardo mantuvo un control de precios que generó mucha inestabilidad política. A causa de dichas circunstancias, se produjo frecuentes huelgas en varias ciudades del país con fuertes reivindicaciones sociales, económicas y laborales. Además, el soporte de nuevos actores como estudiantes y anarquistas fortaleció temporalmente al movimiento obrero en el Perú. ${ }^{71}$ En 1916, el Círculo declaró un año social para profundizar en la doctrina y acción social católicas. El franciscano catalán Francisco Cabré tuvo un papel central durante el año como creador de espacios para discutir la problemática laboral arequipeña y los límites de la acción social católica, y promover una nueva cultura católica del trabajo que contribuyese a la consolidación de un proyecto de país desde las bases morales del cristianismo.

En marzo de 1916, Cabré propuso una línea de acción para el COC a partir de los principios de la "sociología cristiana», con la idea de contribuir a la construcción de una sociedad cristiana de obreros como fin del Círculo. Así, el COC era «a las instituciones prácticas sociales lo que las almácigas al jardín, que no son el jardín, pero suministran plantas para poblarlo» ${ }^{72}$. Es decir, la sociedad debía ser un espacio para formar un trabajador católico comprometido con la construcción de un proyecto mayor, una sociedad regida por principios cristianos. Cabré señaló como la misión del Círculo evitar que el obrero cayese en «las garras de sus enemigos», es decir, de la ignorancia, la impiedad y el socialismo. La ignorancia se combatía con la cultura general que hace del obrero «un ciudadano conciente». Saber leer, escribir, las cuatros operaciones aritméticas, un poco de geografía y de historia universal y patria, permitían al obrero «hacerse respetar» frente a los otros obreros y ciudadanos al poseer instrucción. ${ }^{73}$ De otro lado, la cultura religiosa forjaría un trabajador católico capaz de defender y proponer su fe entre sus pares no católicos y tener una activa práctica de la vida cristiana, cuyos efectos se ven en la

\footnotetext{
${ }^{71}$ Blanchard 1982: 102-119.

72 Cabré 1916: 10.

${ }^{73}$ Ib: 11 .
} 
iglesia y en «labrar la felicidad temporal de la sociedad». ${ }^{74}$ Finalmente, el socialismo debía ser combatido por una cultura social basada en «la doctrina social de la Iglesia y las principales soluciones» y en sus principales conceptos como el "orden social cristiano», la propiedad, la familia, la religión, las clases sociales, entre otros temas. ${ }^{75}$

Desde 1918, Cabré asumió el cargo de subdirector del Círculo. En enero, presentó la conferencia titulada "La unión de la clase obrera» en el cine Arequipa, símbolo de la modernidad urbana de esos años. En el folleto de la conferencia, se seńalaba en la «Prevención» que, a causa del «poco ambiente social que hay en el Perú», algunos lectores podrían pensar que el texto tenía «ribetes rojos de socialismo». ${ }^{76}$ En la conferencia, Cabré disertó sobre la desigualdad de clases sociales y la armonía social. La primera afirmaba «es una aberración, consecuencia del pecado original» ${ }^{77}$, mientras la segunda provenía de Dios. No obstante, la afirmación de Cabré no constituía una crítica radical a la estructura social ni una arenga para su reforma. Al contrario, Cabré reconocía que la desigualdad social de clases era parcialmente "necesaria», en la medida en que cada sujeto tiene «el lugar que Dios nos ha asignado en el cuerpo social». En la desigualdad social, se entrecruzaban el pecado y la organización de la sociedad. Esta era la cuestión social central. Por ello, Cabré reconocía los deseos de los obreros de tener una vida moral, religiosa, ilustrada e, incluso, el deseo de ser en el futuro patrones como legítimos. ${ }^{78}$

Sin embargo, en la Conferencia, Cabré definía la cuestión social como la lucha entre el capital y el trabajo, donde "el capital sin entrańas» destruye la vida de los proletarios y sus hogares, y se aprovecha del poder del dinero para obtener leyes «atentatorias de los derechos del obrero». ${ }^{79} \mathrm{La}$ injusticia cometida por el capitalista contra el trabajador hacía posible en algunos casos «una resistencia pasiva para reivindicar el

${ }^{74}$ Ib.: 12 .

75 Ib.: 14 .

${ }^{76} \mathrm{Ib}$.

77 Ib.: 7 .

${ }^{78}$ Ib.: 9-10.

${ }^{79}$ Ib.: 11-12. 
derecho que el obrero tiene a la vida y a cierta cultura y a un moderado descanso. Me refiero a la huelga, para hacer comprender al capital que nada puede sin el brazo del obrero». La validación moral de la huelga y el apoyo del COC daban cuenta de una mirada más compleja de las relaciones sociales. ${ }^{80}$ Es decir, la sociedad requería ser cambiada, siempre en la clave cristiana, con miras a mantener la armonía social.

Para sostener las luchas, Cabré consideraba que la organización sindical era una necesidad «si en estas luchas no queréis [los obreros] ser arrollados». ${ }^{81}$ La organización de los obreros a través de sindicatos, sociedades mutuas y otras asociaciones constituía una necesidad, pues «el obrero aislado no puede nada; asociado lo puede todo». ${ }^{82}$ Solo la unidad garantizaría una legislación social que favoreciese los intereses obreros en el Perú. El lenguaje de Cabré se acercaba al socialismo en la validación de las estructuras sindicales como en la oposición, aunque no insalvable desde su perspectiva, entre el capitalista y el trabajador. Además, en el marco del final de la Gran Guerra, los anarquistas ya proponían como modelo de organización los sindicatos como una nueva estructura para sostener las luchas sociales. ${ }^{83}$ Cabré se hacía eco de estas innovaciones en la cuestión social y las "cristianizaba» en el marco de la reflexión de la doctrina social católica. Cabré era uno de estos pensadores flexibles respecto de los lineamientos pontificios sobre la huelga y con capacidad de recoger elementos del mundo socialista para aplicarlos a la asociatividad obrera católica.

En enero de 1919, un paro general en Lima y Callao concluyó con la aprobación de la jornada de ocho horas laborales por el gobierno de Pardo. La jornada de ocho horas constituía la mayor victoria del movimiento obrero. El gobierno civilista evitó la expansión del movimiento de lucha por las ocho horas a lo largo del país, y consolidó la actitud paternalista del gobierno central con los trabajadores. En consonancia

\footnotetext{
${ }^{80}$ Desde fines del siglo XIX, los obreros católicos de Bélgica y Alemania consideraban la huelga como un acto legítimo de defensa de sus derechos (Chadwick 1998: 315-318).

${ }^{81}$ Cabré 1918: 15-16.

${ }^{82}$ Ib.: 20.

${ }^{83}$ Blanchard 1982: 113.
} 
con el decreto del gobierno de Pardo, el Círculo promovió la pronta aplicación de la jornada de ocho horas entre los empresarios locales y los socios protectores del COC. En una reunión del 8 de febrero, la Junta Directiva del Círculo felicitó al empresario Luis Blaisdell, gerente de Ferrocarriles del Sur, y a José Pesce, socio protector del Círculo, por conceder la jornada de ocho horas a sus trabajadores. ${ }^{84}$ Con esta actitud, los empresarios católicos mostraron su fidelidad al catolicismo social y al movimiento iniciado por el gobierno central al conceder también ellos la nueva gracia. De esta manera, la lucha política obrera, incluida la del Círculo, se encauzó en el marco legal definido por el gobierno central que ordenaba negociar la jornada laboral a los trabajadores y dueños de empresas y, en caso de no encontrar salida, se debía aplicar la norma de las ocho horas laborales. La movilización dejó de ser una forma de vehiculizar los intereses de los trabajadores para dar paso a la negociación entre patrones y trabajadores. De esta manera, era posible la conciliación y la armonía de las clases sociales como base para el progreso del país, como planteaba el catolicismo social.

El fallido intento de la participación política: el Partido Católico del Perú (1913-1919)

La presencia de liberales y activistas políticos contrarios a la Iglesia activó en Arequipa la preocupación por articular una acción política unificada. En 1912, el civilismo se mostró incapaz de articular la demanda política y social de los nuevos sectores sociales. La victoria presidencial de Guillermo Billinghurst, candidato populista, permitió el ascenso de sectores medios y de nuevas ideologías como el anarquismo y el socialismo. Las clases medias y los grupos populares se vieron representados en el flamante presidente, cuyo gobierno fue interrumpido por un golpe militar en 1914. Además, las elecciones habían mostrado el agotamiento del modelo centralista del civilismo y permitió el surgimiento de alternativas políticas en provincias. ${ }^{85}$

${ }^{84}$ El Deber, 7 de febrero de 1919: 3; y 8 de febrero de 1919: 3.

${ }^{85}$ McEvoy 2017: 353-355. 
En este contexto crítico para el civilismo, en octubre de 1913 en Arequipa, se publicaron las Bases provisionales del Partido Católico tras más de un quinquenio de silencio político de la militancia católica. La finalidad del partido era la «defensa de los principios católicos y su aplicación a todas las manifestaciones de la vida política de la República». ${ }^{86}$ El partido nacía de la reflexión de miembros de la UCA de señores sobre la necesidad de intervenir en la esfera política. En carta del presidente de la UCA Manuel Marina al obispo del Cuzco, Gregorio Castro, se señalaba que «comprendiendo la Unión Católica que no es del todo eficaz remitir a los Poderes Públicos memoriales o actas suscritas para impedir sus sectarios procedimientos contra la Religión Católica, ha resuelto organizar en este departamento el Partido Católico». ${ }^{87}$ Por tanto, se trataba de una iniciativa absolutamente laical para defender la doctrina y la moral, a través de la acción política partidaria. No obstante, la preocupación nacía de la aprobación parlamentaria de la tolerancia de cultos, que concluyó en la aprobación definitiva en noviembre de 1915 de la libertad religiosa. ${ }^{88}$ Es decir, su motivación primera era la defensa del catolicismo y no un proyecto político católico para el país.

El Partido Católico contó desde el inicio con el soporte del obispo de Arequipa, Holguín. En la instrucción pastoral para la Cuaresma de 1914, el prelado centró su reflexión sobre la defensa de la religión, no solo desde la acción apologético-social, sino desde el involucramiento activo de laicos en la política partidaria. ${ }^{89}$ El prelado apelaba a la noción pontificia de "acción católica» como una forma de "fomentar la fe y defenderla de los ataques del error» y de «inyectar en el cuerpo social la savia divina de la moral del Evangelio». ${ }^{90} \mathrm{La}$ «acción católica» era también la labor de «mejoramiento de la condición económica del pueblo», el incremento de la piedad y la vida cristiana, y la «actuación resuelta en la

\footnotetext{
${ }^{86}$ Klaiber 1983.

${ }^{87}$ Klaiber 1983: 160.

${ }^{88}$ Armas Asín 1998: 197-198.

${ }^{89}$ Holguín 1914a: 3.

${ }^{90} \mathrm{Ib}$.
} 
vida pública, en la política del país». ${ }^{91}$ De esta manera, el laico católico estaba convocado a participar de las instituciones estatales para promover el progreso verdadero del país. De acuerdo con el prelado, desentenderse de la política era participar de una «complicidad criminal; porque si son criminales los impíos que socavan los fundamentos del orden social, no lo son menos los que no oponen resistencia a su obra nefanda». ${ }^{92}$

El obispo señalaba como obligación «en conciencia» de todo católico en Arequipa la organización e inscripción en el Partido Católico del Perú. Se debía inscribir el partido en los registros y promover la inscripción de los laicos no solo en el Cercado de la ciudad sino en todas las provincias de la diócesis. Para ello, facilitaba las estructuras diocesanas. El prelado resaltó la importancia del derecho a votar y la relación con los intereses del país, la obligatoriedad del voto y la militancia católica en el ejercicio del voto. De esta manera, Holguín reconocía el valor de la práctica electoral y legitimaba la validez del sistema político. Esta actitud teológica era signo del proceso de modernización al interior del pensamiento y pastoral católicas y una adaptación al modelo político latinoamericano. Es decir, como León XIII, un reconocimiento de la validez del orden político. Para el prelado era «deber ineludible de conciencia que todo católico y patriota, actuar en la Política del país con la mayor eficacia posible». Por su parte, al sacerdote le tocaba la labor de «adoctrinar a los ciudadanos en los deberes que como tales deben cumplir» y, por tanto, debe «ejercer su ministerio pastoral en el campo de la Política». ${ }^{93}$ Con ello, monseñor Holguín se mostraba a favor de una comprensión amplia de la noción de «acción católica» como participación de los laicos en la política partidaria para obtener una representación política del catolicismo en los órganos de gobierno. La postura de Holguín implicaba el reconocimiento de la diversidad de opciones políticas en el país.

En 1915, los miembros de la Junta Departamental de Arequipa del Partido, cuyo presidente era Lorenzo Montoya y vicepresidentes, Manuel Marina y Carlos Federico Tester, redactaron una presentación de los

\footnotetext{
${ }^{91} \mathrm{Ib}$.

$92 \mathrm{Ib}$.

${ }^{93}$ Ib.: 4 .
} 
fines del Partido Católico del Perú. ${ }^{94}$ En ella, reclamaban «distinguir» la religión de la política y la moral; sin embargo, la religión «es la causa informadora y determinante de la Moral, como lo es también de la Política». ${ }^{95}$ La preocupación central era la moral pública que se perfecciona con los principios del catolicismo y la estabilidad política del país frente a los partidos sin principios fijos y reemplazados por caudillos. ${ }^{96}$ La Junta rechazó el apelativo de «conservadores», pues

si en la conciencia pública está que de todos los ámbitos del país se alza un grito de angustia, porque en todo él se sienten síntomas alarmantes de descomposición y de derrumbamiento social, ¿qué sería lo que quisiéramos conservar nosotros?

Si somos los primeros en pensar que este país necesita un renovamiento; si las masas se sienten decepcionadas de todos los partidos políticos y su la corrupción de estos corre pareja con el indiferentismo religioso y el positivismo moral que han tratado y tratan de infiltrar en las costumbres primero y en las leyes después, ¿cómo alzaríamos bandera conservadora??7

La presentación recogía la difícil situación política de representatividad abierta por la crisis del gobierno de Billinghurst. En el organigrama del partido, se destacaba que había que «ir hasta el fondo mismo del pueblo a conocer sus necesidades». Además, la estructura buscaba evitar "ese centralismo absorvente» de Lima que destruye y corrompe la política y, más bien, se proponía «una democracia sincera» que incluyese a las

${ }^{94}$ Los otros miembros de la Junta Departamental de Arequipa eran los secretarios E. Adolfo Chaves y Luis O. De Piérola, el prosecretario J. Enrique Velarde Chocano, el tesorero Augusto Benavides, el tesorero auxiliar Carlos A. Artieda y los vocales Rubén Bustamante, Manuel Guillermo de Castresana, Abraham de Vinatea, José Domingo Muñoz Nájar, Roberto E. López de Romaña, Manuel Barreda y Barreda, Juan José Soto Landázuri, Luis Fernando Llosa, Carlos A. Bouroncle, J. Luis de Romańa, Roberto Chocano, Teófilo Zuzunaga y Mariano Gaitán. Los delegados de las Juntas Distritales eran Manuel Francisco López (Cayma), Luis M. Delgado (Tiabaya), Luis Arrisueño Guillén (Paucarpata), Mariano González Carpio (Quequeña) y Víctor F. Bernal (Characato) (Partido Católico del Perú 1916: 8-9).

${ }^{95}$ Partido Católico del Perú 1916: 4.

96 Ib.: 5 .

97 Ib.: 5-6. 
regiones. ${ }^{98}$ De esta manera, los católicos arequipeños defendían el derecho de la región a tener igualdad de voz en la política y, por tanto, se hacían del discurso descentralista de la época. ${ }^{99}$ Las reivindicaciones religiosas y políticas del país eran articuladas desde la plataforma partidaria católica de Arequipa. Desde inicios de 1916, como signo de su descentralización, se organizaron directivas del Partido Católico en los pueblos arequipeños de Ocoña, Huambo, Pampacolca, Ilabaya y San Juan de Siguas. ${ }^{100}$

La organización del Partido Católico en Arequipa coincidió con el surgimiento de nuevas alternativas políticas. En 1915, en Lima surgieron dos propuestas políticas para afrontar la crisis: el Partido Nacional Democrático, fundado por el intelectual liberal José de la Riva-Agüero, y la Convención de los partidos políticos que agrupaba a civilistas, liberales y constitucionalistas. El partido de Riva-Agüero, dado su fuerte perfil intelectual, no logró cuajar más allá de círculos académicos reformistas y críticos del civilismo. Sin embargo, la Convención logró articular nuevamente una propuesta política que dejó fuera a las nuevas fuerzas sociales emergidas en 1912. El candidato de la Convención José Pardo se hizo con la presidencia en $1915 .{ }^{101}$ El Partido Católico, a pesar del marco institucional de la Iglesia, no logró cuajar como un partido político de alcance nacional y menos un proyecto político de alcance nacional. Las diferencias políticas también mellaban la unidad política de los católicos.

En marzo de 1917, en el mensaje de cuaresma, monseñor Holguín criticó abiertamente a «esos católicos a medias que creen en la Santa Madre Iglesia Católica, Apostólica y Romana, y al mismo tiempo profesan doctrinas terminantemente condenadas por ella». ${ }^{102}$ El Domingo de Ramos, el prelado denunció a los católicos que no votaron por el Partido Católico. Ellos afirmaban «hacen lujo de ser católicos y que a título de tales han medrado y pretenden encumbrarse más, se les oyó vitorear

\footnotetext{
98 Ib.: 7.

99 Sobre la tradición descentralista en Arequipa y el sur andino, véase Deustua y Rénique 1984.

${ }^{100}$ Garreaud Indacochea 2015, 2: 105 .

${ }^{101}$ McEvoy 2017: 362-369.

${ }^{102}$ Holguín 1917a: 7.
} 
estruendosamente al Partido Liberal y proclamar a voz en cuello sus pretendidos triunfos». ${ }^{103}$ La denuncia del prelado equiparó a dichos católicos con Judas, pues «venden a su divino Maestro por un puñado de dinero, por un vil interés, por un miserable respeto humano». ${ }^{104}$ El polémico sermón fue criticado por los liberales. Incluso el diario limeño La Prensa criticó al obispo por convertir el templo en casa política e intervenir en ella. ${ }^{105}$

Un grupo de laicos respondió a los ataques contra Holguín. Ellos destacaron la "grave obligación que tienen los católicos de intervenir en la política del país para defender los intereses trascendentales de la Religión y de la patria». ${ }^{106}$ Los laicos reconocían la pluralidad de actores en la arena política y la necesidad, por tanto, de participar en ella. Ellos consideraban que debía existir «un credo político común» entre los católicos. ${ }^{107}$ Calificaban como "católicos a medias» a los que no se sumaban a la opción política católica. Para ellos, era imposible considerar la posibilidad de que un católico pudiese votar por otras opciones políticas y menos vincularse a agrupaciones críticas de la Iglesia católica. De esta manera, la pluralidad política entre los creyentes era objetada por quebrar la unidad doctrinal, moral e ideológica del catolicismo. No existía un espacio público católico, como el surgido en el periodo posterior al Vaticano II en el Perú. No se trataba de una debilidad política, sino de una manera de comprender el catolicismo propio del siglo XIX y de la primera mitad del XX, donde se destacaba la unidad ideológica, institucional y doctrinal como un elemento cohesionador para enfrentarse a las nuevas ideologías políticas.

Hacia finales de 1918, el nuncio apostólico en el Perú monseñor Lorenzo Lauri, en contra de la postura del arzobispo de Lima Emilio Lissón, alentó al obispo de Arequipa a coordinar y organizar el voto católico para las elecciones de $1919 .{ }^{108}$ La cercanía de los candidatos presiden-

\footnotetext{
${ }^{103}$ Holguín 1917b.

${ }^{104}$ Holguín 1917b.

${ }^{105}$ Garreaud Indacochea 2015, 2: 111.

${ }^{106}$ Candente actualidad politica 1917: 5.

107 Partido Católico del Perú 1916: 1.

${ }^{108}$ Ara Goñi 2012: 163.
} 
ciales, el civilista Antero Aspíllaga y el constitucionalista Augusto Leguía, con los liberales y protestantes hacía necesario un voto católico fuerte canalizado a través del Partido Católico. No obstante, el apoyo explícito del nuncio, Holguín en carta a Lauri del 4 de febrero de 1919, — previo a las elecciones - reconocía la dificultad para organizar el Partido Católico en Arequipa, que había entrado en receso; especialmente, luego de que Lissón se declarase opuesto al mismo. Sin haberse pronunciado sobre el tema, consideraba que, a causa de la desorganización de los católicos, se obtendría poco impacto en la elección de representantes. ${ }^{109}$ Las desavenencias de los obispos peruanos sobre la participación política partidaria de los católicos impidieron la consolidación de un partido católico nacional activo en la vida política y pública, como ocurrió en otros países en Europa y América Latina. Hacia finales de 1919, el Partido Católico se encontraba en total decadencia. ${ }^{10}$

\section{CONCLUSIONES}

En Arequipa, el resurgimiento católico tuvo un rostro predominantemente laical, aunque sí estuvo profundamente vinculado a los obispos de turno y su comprensión de la realidad local. Las organizaciones católicas estudiadas muestran la compleja relación del catolicismo con la política y la sociedad en Arequipa. La relación tuvo dos paradigmas asociados a los episcopados de Huerta y Ballón, por un lado, y de Holguín, por el otro. El primer momento se dio entre 1885 y 1905, mientras que el segundo se extendió desde 1906 hasta 1919. En el caso del primer paradigma, la sensación de persecución alimentó fuertemente la resistencia apologético-política. Los sectores católicos buscaban apelar a la catolicidad del estado y a la "cristianización» del estado y la sociedad, es decir, a una monopolización de las instituciones nacionales y sus

${ }^{109}$ Ara Goñi 2012: 157.

${ }^{110}$ La desaparición del Partido Católico significó el regreso de las Actas como formas públicas para realizar presión política sobre el estado. En la Memoria de 1924 de la UC de señoras, se informa del envío al presidente del Senado de una representación firmada por las señoras de la UC para solicitar que no se sancione como ley la laicización de los cementerios (Unión Católica de señoras 1924: 5-6). 
agentes. Con León XIII, se introdujo un cambio de este paradigma. El papa admitió la validez parcial de la democracia y las nociones políticas modernas, así como la necesidad de que los católicos se involucrasen en la vida social y política. No obstante, el cambio introducido por León XIII, la crisis del primer paradigma ocurrió en Arequipa a causa de la renuncia del obispo Ballón en 1905. Durante el segundo momento, los católicos mantuvieron un papel apologético, pero reconocieron que la «cristianización» solo era posible por la activa acción en la esfera pública y política de la militancia católica. Por ello, el catolicismo social y la acción política partidaria fueron centrales en este paradigma.

A lo largo del tránsito entre los dos paradigmas, se identifican tres elementos. En primero consiste en el desplazamiento hacia la esfera pública — social y política—, encabezado por la militancia católica. La prensa, las protestas públicas, las asociaciones y los partidos católicos fueron maneras de involucrarse en el debate político y social, en un contexto de secularización institucional del estado y la sociedad. En este proceso, los laicos y laicas fueron actores fundamentales de la nueva presencia de la Iglesia en el mundo. Sin dejar de lado la dependencia clerical y doctrinal, el laicado se volvió crucial en la defensa de la fe y su promoción en la sociedad y el estado. Las actividades de las sociedades católicas de Arequipa dan cuenta del explícito deseo de moldear la sociedad y la política acorde a la comprensión de la realidad promovida por el discurso romano y episcopal. En esta línea, se entienden el trabajo social y moral de las señoras de la UCA, el programa del Círculo de Obreros Católicos que buscaba fortalecer la identidad del trabajador católico como forjador de la armonía social y el progreso, y la intervención fallida en política del Partido Católico. En estos casos, a pesar de buscar catolizar la sociedad y el estado, los laicos reconocían - no necesariamente aceptaban — la emergente pluralidad de opciones de vida y acción política en Arequipa. Por ello, a su estilo, los laicos estaban implicados en el anhelo de forjar un estado y una sociedad regidas por los principios morales del catolicismo. Los laicos y laicas arequipeńos fueron activos defensores y promotores de la «sociedad católica» en Arequipa y el Perú. 
Un segundo elemento es la articulación realizada por el laicado arequipeño entre su identidad católica y su identidad regional. Este proceso se produjo por la recepción episcopal del discurso pontificio, como por la adaptación de la militancia católica al contexto local de Arequipa. Los laicos también se apropiaron de las demandas locales como la descentralización y la ruptura de la primacía de Lima en la política peruana. Eran también sus demandas como arequipeños en un contexto de creciente centralización. Los estatutos del Partido Católico muestran la negociación de la identidad católica y arequipeña, pues se incorporaron las demandas regionales como la crítica al proceso de centralización. Asimismo, la oposición a la centralista Lima era acompañada de una crítica por la presencia de liberales y masones entre los liderazgos limeños, en clara contraposición con los liderazgos católicos de Arequipa.

Finalmente, el tercer elemento de la militancia católica permite afirmar que, en el proceso de ser los brazos activos de la Iglesia en la sociedad y la esfera pública, los laicos asumieron una mayor consciencia de su pertenencia eclesial, o de ser «apóstol» como se decía de las señoras de la UC en 1914. En el discurso de inauguración del Centro de Acción Católica de Arequipa, Lorenzo Montoya, prominente laico y miembro de la Unión Católica, describía su trabajo y el de otros católicos como el de «soldados voluntarios del apostolado laico» que «venimos a engrosar sus filas y a librar las buenas batallas al lado del orden, del bien, de la justicia, de la instrucción y del trabajo honrado». ${ }^{11}$ El término "apostolado laico» señalaba el encargo laical por la recristianización del mundo para que «reine Dios en el corazón del hombre y en la voluntad del pueblo». ${ }^{112}$ La actividad social y política tenía una dimensión religiosa y eclesial, en la que los laicos eran fundamentales para lograr que «reine Dios». Esta nueva mirada del trabajo militante transformó radicalmente el rol de los laicos dentro de la Iglesia en las décadas siguientes y adquirió su forma eclesiológica definitiva en el Concilio Vaticano II (1962-1965).

${ }^{111}$ Montoya 1905: 11.

112 Ib.: 15 . 


\section{BIBLIOGRAFÍA}

Anderson, Margaret. 2000. «The Divisions of the Pope: The Catholic Revival and Europe's Transition to Democracy». En Ivereigh, Austen (ed.). The Politics of Religions in an Age of Revival. Londres: University of London, 22-42.

Anónimo. 1917. Candente actualidad politica. Diálogos joco-serios sobre politica católica y sobre los deberes de los católicos en esta materia. Publicados en "El Deber" de Arequipa, escritos y coleccionados por Valmala. Arequipa: Imprenta de El Deber.

Ara Goñi, Jesús Angel. 2012. «La Acción Católica y la política en el Perú: la posición de los prelados peruanos a principios de la década de 1920». Boletín Americanista. Número 65: 147-166.

Ara Goñi, Jesús Angel. 2019. La construcción de la Acción Católica en el Perú. Lima: Pontificia Universidad Católica del Perú.

Armas Asín, Fernando. 1998. Liberales, protestantes y masones. Modernidad y tolerancia religiosa. Perú, siglo XIX. Lima: Pontificia Universidad Católica del Perú, Centro de Estudios Regionales Andinos Bartolomé de Las Casas.

Armas Asín, Fernando. 2005. «Perú, 1850-1950. La construcción del patrimonio religioso». Revista de Turismo y Patrimonio. Número 5: 9-21. https://doi. org/10.24265/turpatrim.2005.n5.01

Ballón, Manuel. 1898. Carta Pastoral que el Ilustrísimo y Reverendísimo Monseñor Manuel Segundo Ballón dirige al Clero y fieles de su Diócesis al tomar posesión de ella. Arequipa: Imprenta de La Bolsa.

Ballón, Manuel. 1901. Carta Pastoral que el Ilustrísimo y Reverendísimo Dr. D. Manuel Segundo Ballón, obispo de Arequipa, dirige al Clero y fieles de su Diócesis, recomendando la lectura de la encíclica que Su Santidad el Papa León XIII ha publicado acerca de la democracia cristiana. Arequipa: Tipografía Muñiz.

Ballón Lozada, Héctor. 2001. «Crisis de la autoridad eclesiástica y sus luchas con los liberales de la tercera generación y los protestantes. 1900-1940». Historia. Revista de la Escuela profesional de historia, UNAS. Número 4: 155-165.

Bandini, Manuel Antonio. 1895. El Iltmo y Rmo. Sr. Arzobispo de Lima Dr. D. Manuel Antonio Bandini da a conocer a los católicos del Perú, la defensa que, hasta el presente, se ha hecho de los derechos de la Iglesia y de los de sus Pastores, combatiendo el proyecto presentado a la H. Cámara de Diputados sobre administración de bienes de los Conventos. Lima: Imprenta y Librería de Carlos Prince.

Blanchard, Peter. 1982. The origins of the Peruvian Labor Movement, 1883-1919. Pittsburgh: University of Pittsburgh Press.

Blasco, Inmaculada. 2005. «Ciudadanía y militancia católica femenina en la España de los años veinte». Ayer. Volumen 57, número 1: 223-246.

Burleigh, Michael. 2005. Earthly Powers: Religion and Politics in Europe from the French Revolution to the Great War. Londres: Harper Collins. 
Cabré, Francisco. 1916. Bosquejo de un programa de Círculo de Obreros Católicos. Conferencia dada en el "Círculo de Obreros Católicos" de Arequipa, con motivo de celebrarse el XX aniversario de su fundación. Arequipa: Tipografía Medina.

Cabré, Francisco. 1918. La unión de la clase obrera. Conferencia dada en el "Circulo de Obreros Católicos» en el cine de Arequipa, el día 27 de enero de 1918. Arequipa: Tipografía Cáceres.

Cárdenas Ayala, Elisa. 2018. Roma: el descubrimiento de América. México: El Colegio de México. https://doi.org/10.2307/j.ctv6hp370

Carpio Muñoz, Juan Guillermo. 1990. «La inserción de Arequipa en el desarrollo mundial del capitalismo (1867-1919)». En Neira Avendaño, Máximo et al. (eds.). Historia General de Arequipa. Arequipa: Fundación M.J. Bustamante de la Fuente, 489-578.

Chadwick, Owen. 1998. A History of the Popes 1830-1914. Oxford: Oxford University Press. https://doi.org/10.1093/0198269226.001.0001

Cid, Gabriel. 2014. "Las señales de los últimos tiempos”. Laicidad y escatología en el pensamiento católico hispanoamericano del siglo XIX». Hispania Sacra. Volumen 66, número 133: 179-207. https://doi.org/10.3989/hs.2013.050

Círculo de Obreros Católicos de Arequipa. 1897. Estatutosy Reglamentos del "Círculo de Obreros Católicos» de Arequipa. Arequipa: Tipografía Cáceres.

Círculo de Obreros Católicos de Arequipa. 1901. Reglamentos del Círculo de Obreros Católicos. Aprobados por el Comité Directivo en sesión de 26 de octubre de 1901. Arequipa.

Clark, Christopher y Wolfram Kaiser (eds.). 2003. Culture Wars. Secular-Catholic Conflict in Nineteenth-Century Europe. Cambridge: Cambridge University Press. https://doi.org/10.1017/CBO9780511496714

Congreso Católico del Perú. 1897. Anales del Primer Congreso Católico del Perú, inaugurado en Lima el día 8 de noviembre de 1896. Lima: Imprenta de la Librería Clásica y Científica.

Creppell, Ingrid. 2010. «Secularization: religion and the roots of innovation in the political sphere». En Katznelson, Ira y Gareth Stedman Jones (eds.). Religion and the Political Imagination. Cambridge: Cambridge University Press, 23-45. https://doi.org/10.1017/CBO9780511779510.002

Cubas Ramacciotti, Ricardo. 2008. "Catolicismo y movimiento obrero en el Perú: El caso de los Círculos Obreros Católicos (1890-1930)». En Armas Asín, Fernando, Carlos Aburto, Juan Fonsenca y José Ragas (eds.). Políticas divinas: Religión, diversidad y política en el Perú contemporáneo. Lima: Instituto RivaAgüero, 229-250.

Cubas Ramacciotti, Ricardo. 2017. «La Rerum novarum y su influencia en el catolicismo social peruano: La experiencia de los Círculos de Obreros Católicos 
(1891-1931)». Revista de Historia y Geografía. Número 36: 21-43. https://doi. org/10.29344/07194145.36.333

Deustua, José y José Luis Rénique. 1984. Intelectuales, indigenismo y descentralismo en el Perú 1897-1931. Cusco: Centro de Estudios Regionales Andinos Bartolomé de las Casas.

Espinoza, Juan Miguel. 2015. «Entre criollos y modernos: género, raza y modernidad criolla en el proyecto editorial de la revista Variedades (Lima, 1908-1919)». Histórica. Volumen 39, número 1: 97-136.

Fonseca, Juan. 2002. Misioneros y civilizadores. Protestantismo y modernización en el Perú (1915-1930). Lima: Pontificia Universidad Católica del Perú.

Fonseca, Juan. 2003. «Los protestantes, el Estado y la legislación modernizadora en el Perú (1889-1930)». Boletín del Instituto Riva-Agüero. Número 30: 215-232.

García Jordán, Pilar. 1988. «Iglesia y vida cotidiana en el Perú finisecular. Conflictos alrededor de la religión, el matrimonio y la muerte». Boletín Americanista. Número 38: 63-75.

García Jordán, Pilar. 1991. Iglesia y poder en el Perú contemporáneo, 1821-1919. Cusco: Centro de Estudios Regionales Andinos Bartolomé de las Casas.

Garreaud Indacochea, Emilio. 2015. Un siglo de solidaridad con el pobre. La acción social de la Iglesia en Arequipa. Volumen 2. La acción social de la Iglesia en Arequipa. San José: Universidad Juan Pablo II.

Hernández, Miguel-Ángel. 2016. En defensa de los sagrados intereses. Historia religiosa de la diócesis de Zamora durante la Restauración (1875-1914). Salamanca: Ediciones Universidad de Salamanca.

Holguín, Manuel. 1914a. Instrucción Pastoral. Sobre la defensa de la religión que el Iltmo. Obispo de Arequipa, Monseñor Fr. Mariano Holguin, O.F.M., dirige al clero y fieles de su Diócesis, con motivo de la Cuaresma. Arequipa.

Holguín, Mariano. 1914b. «Palabras con que agradeció la fiesta nuestro Ilustrísimo Prelado», en Liga contra Espectáculos Inmorales, La velada en honor de los obreros. Arequipa, 4 de octubre de 1914. Arequipa: Tipografía Cáceres.

Holguín, Manuel. 1917a. Instrucción pastoral sobre La Religión a medias que el Iltmo. y Rdmo. Mons. Fr. Mariano Holguin, Obispo de Arequipa dirige al clero y los fieles de su Diócesis con motivo de la presente Cuaresma. Arequipa: Tipografía Cuadros.

Holguín, Manuel. 1917b. Alocución del Iltmo. Sr. Obispo. A los caballeros que comulgaron en la Iglesia de la Compañia, el Domingo de Ramos del presente año. Arequipa. Huerta, Juan Ambrosio. 1886. Instrucción Pastoral que el Obispo de la Diócesis Dr. D. Juan Ambrosio Huerta, dirige al Consejo Directivo y a todos los miembros de la "Unión Católica» de Arequipa. Arequipa: Imprenta de la Crónica Imparcial. Iberico Ruiz, Rolando. 2016. La república católica dividida: ultramontanos y liberalesregalistas (Lima, 1855-1860). Lima: Instituto Riva-Agüero, Fundación Manuel J. Bustamante De la Fuente. 
Iberico Ruiz, Rolando. 2020. «De Juan Ambrosio Huerta a Mariano Holguín: episcopado, ultramontanismo y modernidad en Arequipa (1880-1935)». Allpanchis. Volumen 48, número 86: 13-58. https://doi.org/10.36901/allpanchis.v47i86.1171

Ivereigh, Austen. 2000. «The Politics of Religions in an Age of Revival». En Ivereigh, Austen (ed.). The Politics of Religions in an Age of Revival. Londres: University of London, 1-21.

Jedin, Hubert. 1978. Manual de Historia de la Iglesia. Tomo VIII. La Iglesia entre la adaptación y la resistencia. Barcelona: Editorial Herder.

Klaiber, Jeffrey. 1983. "La escasez de sacerdotes en el Perú: una interpretación histórica». Histórica. Volumen 7, número 2: 157-177.

Klaiber, Jeffrey. 1988. La Iglesia en el Perú. Su historia social desde la independencia. Lima: Pontificia Universidad Católica del Perú.

Liga contra Espectáculos Inmorales. 1914a. Con licencia eclesiástica. Arequipa: Tipografía Cáceres.

Liga contra Espectáculos Inmorales. 1914b. La velada en honor de los obreros. Arequipa, 4 de octubre de 1914. Arequipa: Tipografía Cáceres.

López Menéndez, Marisol. 2017. «Mártires abandonados: militancia católica, memoria y olvido en México». Sociedad y Religión. Volumen 48, número 27: 97-129.

Lynch, John. 2012. Dios en el Nuevo Mundo. Una historia religiosa de América Latina. Barcelona: Crítica.

Martin, Gillemette. 2012. "La "Roma del Perú" au tournant du siècle: catholicisme, libéralisme et identité locale à Arequipa (1890-1915)». Amnis. Revue d'études des sociétés et cultures contemporaines Europe-Amérique. Número 11. https://doi. org/10.4000/amnis. 1642

McEvoy, Carmen. 2017. La utopia republicana. Ideales y realidades en la formación de la cultura política peruana (1871-1919). Lima: Pontificia Universidad Católica del Perú.

Montoya, Lorenzo. 1905. «Discurso. En Centro de Acción Católica». Estatutos del Centro de Acción Católica de Arequipa. Arequipa: Imprenta y Tipografía de El Deber, 9-17.

Partido Católico del Perú. 1916. Estatutos del Partido Católico del Perú. Arequipa: Tipografía Cáceres.

Pike, Frederick. 1967. "Heresy, Real and Alleged, in Peru: An Aspect of the Conservative-Liberal Struggle, 1830-1875». The Hispanic American Review. Volumen 47, número 1: 50-74. https://doi.org/10.1215/00182168-47.1.50

Romero, Catalina. 2008. «Religión y espacio público: catolicismo y sociedad civil en el Perú». En Romero, Catalina (ed.). Religión y Espacio Público. Lima: Pontificia Universidad Católica del Perú, 17-36. 
Sobrevilla, Natalia. 2002. "The Influence of the European 1848 Revolutions in Peru». En Thoms, Guy (ed.). The European Revolutions of 1848 and the Americas. Londres: University of London, 191-216.

Sobrevilla, Natalia. 2004. «El proyecto liberal y la Convención de 1855». En McEvoy, Carmen (ed.). La experiencia burguesa en el Perú (1840-1940). Madrid, Frankfurt: Iberoamericana, Vervuert, 225-246. https://doi. org/10.31819/9783964563958-010

Taylor, Charles. 2014. La era secular. Tomo I. Barcelona: Editorial Gedisa.

Uertz, Rudolf. 2011. «The Catholic Church after the French Revolution (17891848)». En Schmidt, Peer; Dorsch, Sebastian y Hedwig Herold-Schmidt (eds.). Religiosidad y Clero en América Latina - Religiosity and Clergy in Latin America (1767-1850). La Época de las Revoluciones Atlanticas - The Age of Atlantic Revolutions. Colonia, Viena: Böhlay Verlag, 55-76. https://doi.org/10.7788/ boehlau. 9783412214661.55

Unión Católica de Arequipa. 1887. Exposición de la Unión Católica de Arequipa a sus conciudadanos. Arequipa: Tipografía Cáceres.

Unión Católica de Señoras. 1908. Memoria de la «Unión Católica de Señoras». Arequipa: Tipografía Medina.

Unión Católica de Señoras. 1909. Memoria de los trabajos de la "Unión Católica de Señoras». Presentado por el R.P. Raimundo Zamarripa S.J., Director de dicha Institución. Arequipa: Imprenta de El Deber.

Unión Católica de Señoras. 1910. Memoria de los trabajos de la "Unión Católica de Señoras». Presentado por el R.P. Raimundo Zamarripa S.J., Director de dicha Institución. Arequipa: Imprenta de El Deber.

Unión Católica de Señoras. 1911. Memoria de los trabajos de la "Unión Católica de Señoras". Presentado por el R.P. Martín Mendoza S.J., Director de dicha Institución. Arequipa: Imprenta de El Deber.

Unión Católica de Señoras. 1912. Memoria de los trabajos de la "Unión Católica de Señoras». Presentado por el R.P. Jesús Margañón S.J., Director de dicha Institución. Arequipa: Imprenta de El Deber.

Unión Católica de Señoras. 1913. Memoria de los trabajos de la "Unión Católica de Señoras». Presentado por el R.P. Margañón S.J., Director de dicha Institución. Arequipa: Imprenta de El Deber.

Unión Católica de Señoras. 1914. Memoria de los trabajos de la "Unión Católica de Señoras". Presentado por el R.P. Jesús Margañón S.J., Director de dicha Institución. Arequipa: Tipografía Cáceres.

Unión Católica de Señoras. 1918. Memoria de los trabajos de la "Unión Católica de Señoras». Presentado por el R.P. Luis Menéndez S.J., Director de dicha Institución. Arequipa: Tipografía Gutemberg. 
Unión Católica de Señoras. 1920. Memoria de los trabajos de la «Unión Católica de Señoras». Presentado por el R.P. Luis Menéndez S.J., Director de dicha Institución. Arequipa: Tipografía Gutemberg.

Unión Católica de Señoras. 1921. Memoria de los trabajos de la «Unión Católica de Señoras». Presentado por el R.P. Luis Menéndez S.J., Director de dicha Institución. Arequipa: Tipografía Gutemberg.

Unión Católica de Señoras. 1923. Memoria de los trabajos de "Unión Católica de Señoras». Presentado por el R.P. Nicanor Palomino S.J., Director de dicha Institución. Arequipa: Tipografía Gutemberg.

Unión Católica de Señoras. 1924. Memoria de la "Unión Católica de Señoras". Año 1924. Arequipa: Tipografía y Encuadernación Cuadros.

Unión Católica de Señoras. 1926. Memoria de la "Unión Católica de Señoras". Año 1926. Arequipa: Tipografía y Encuadernación Cuadros.

Vaca, Agustín. 2005. «Formas de militancia católica 1900-1930». Estudios jaliscienses. Número 59: 62-74.

Fecha de recepción:21/VII/2021 Fecha de aceptación: 20/VIII/2021 